\title{
1 The food web of Potter Cove (Antarctica): complexity, structure and function
}

2 Tomás I. Marina ${ }^{1,2,3}$, Vanesa Salinas ${ }^{1,2}$, Georgina Cordone ${ }^{1,2}$, Gabriela Campana ${ }^{3,4}$, María

3 Eugenia Moreira ${ }^{4}$, Dolores Deregibus ${ }^{4}$, Luciana Torre ${ }^{5,6}$, Ricardo Sahade ${ }^{5,6}$, Marcos Tatián ${ }^{5,}$

$4{ }^{6}$, Esteban Barrera Oro ${ }^{1,4,9}$, Marleen De Troch ${ }^{7}$, Santiago Doyle ${ }^{2}$, María Liliana Quartino ${ }^{8,9}$,

5 Leonardo A. Saravia ${ }^{2}$, Fernando R. Momo ${ }^{2,3}$

$6 \quad{ }^{1}$ Consejo Nacional de Investigaciones Científicas y Técnicas (CONICET)

$7 \quad 2$ Instituto de Ciencias Universidad Nacional de General Sarmiento, J.M. Gutierrez 1150 (1613),

8 Los Polvorines, Argentina

$9 \quad 3$ INEDES, Universidad Nacional de Luján, CC 221, 6700 Luján, Argentina

$10{ }^{4}$ Instituto Antártico Argentino, Cerrito 1248 (C1010AAZ), Ciudad Autónoma de Buenos Aires,

11 Argentina

$12{ }^{5}$ Facultad de Ciencias Exactas, Físicas y Naturales, Universidad Nacional de Córdoba, Av.

13 Vélez Sarsfield 299 (5000), Córdoba, Argentina

$14{ }^{6}$ Instituto de Diversidad y Ecología Animal (Consejo Nacional de Investigaciones Científicas y

15 Técnicas)

$16{ }^{7}$ Marine Biology, Ghent University, Krijgslaan 281/S8, (B-9000), Ghent, Belgium

$17{ }^{8}$ Dirección Nacional del Antártico, Instituto Antártico Argentino, Departamento de Biología

18 Costera, 25 de mayo 1143, San Martin (CP 1650), Buenos Aires, Argentina

$19{ }^{9}$ Museo Argentino de Ciencias Naturales B. Rivadavia. Av. A. Gallardo 470 (C1405DJR),

20 Buenos Aires, Argentina

21 E-mail: tomasimarina@ gmail.com 


\section{Abstract}

23 Knowledge of the food web structure and complexity are central to better understand ecosystem

24 functioning. A food-web approach includes both species and energy flows among them,

25 providing a natural framework for characterizing species' ecological roles and the mechanisms

26 through which biodiversity influences ecosystem dynamics. Here we present for the first time a

27 high-resolution food web for a marine ecosystem at Potter Cove (northern Antarctic Peninsula).

28 Eleven food web properties were analyzed in order to document network complexity, structure

29 and topology. We found a low linkage density (3.4), connectance (0.04) and omnivory

30 percentage (45), as well as a short path length (1.8) and a low clustering coefficient (0.08).

31 Furthermore, relating the structure of the food web to its dynamics, an exponential degree

32 distribution (in- and out-links) was found. This suggests that the Potter Cove food web may be

33 vulnerable if the most connected species became locally extinct. For two of the three more

34 connected functional groups, competition overlap graphs imply high trophic interaction between

35 demersal fish and niche specialization according to feeding strategies in amphipods. On the other

36 hand, the prey overlap graph shows also that multiple energy pathways of carbon flux exist

37 across benthic and pelagic habitats in the Potter Cove ecosystem. Although alternative food

38 sources might add robustness to the web, network properties (low linkage density, connectance

39 and omnivory) suggest fragility and potential trophic cascade effects.

40 Key words: Ecological networks; Structure; Degree distribution; Marine ecosystem;

41 Antarctica. 


\section{1. Introduction}

44 Food web (FW) characterization is essential to understanding ecology as a way to describe and

45 quantify the complexity of ecosystems by identifying the trophic interactions among species

46 (Bascompte 2009). The framework of ecological network analysis could also be used to quantify

47 the effects of the environment and how indirect effects of such interactions influence overall

48 ecosystem properties (Brose and Dunne 2009).

49 Since the early 2000s, ecological networks from marine systems have received more attention

50 answering an emphatical call of Raffaelli (2000) for more research on marine webs. In this sense,

51 indices derived from Ecological Network Analysis (ENA), a system-oriented methodology to

52 analyze within system interactions (Fath et al. 2007), have been used to investigate trophic

53 interactions in marine ecosystems (Baird et al. 2007, Ulanowicz 2011, Wuff et al. 2012,

54 Heymans et al. 2014). Among marine webs, polar FWs recently began to be considered in the

55 frame of FW theory (e.g. Jacob et al. 2006, Bodini et al. 2009, de Santana et al. 2013). Moreover,

56 some conclusions on the effects of global warming on Arctic and Antarctic marine FWs have

57 been proposed (de Santana et al. 2013, Kortsch et al. 2015).

58 Potter Cove is an Antarctic fjord that suffers from the impact of the high rate of warming

59 occurring in Western Antarctic Peninsula (Quartino et al. 2013, Deregibus et al. 2016). The

60 abundant and rich epibenthic fauna has been changing under the influence of considerable

61 sediment inputs and other effects derived from ice melting (Pasotti et al. 2015a, Sahade et al.

62 2015). The way in which network properties can be modified under climate change is in general,

63 poorly known (Petchey et al. 2010, Walther 2010, Woodward et al. 2010). To understand the

64 community-level consequences of the rapid polar warming, Wirta et al. (2015) suggested that we

65 should turn from analyses of populations, population pairs, and isolated predator-prey couplings 
66 to considering all the species interacting within communities. If species affected by perturbations

67 possess key functional roles in the FW, then the potential higher order, indirect effects of those

68 perturbations on the entire FW structure can be dramatic (Kortsch et al. 2015). Knowing that

69 climate change effects are already occurring in Potter Cove ecosystem and that ecosystems

70 respond to perturbations as a whole, a network approach could contribute to a better

71 understanding of changes in the ecosystem's synthetic properties like resilience or stability. A

72 representative roadmap of trophic interactions of Potter Cove will allow testing for the impact of

73 ongoing climate change effects (e.g. glacier retreat, loss of ice shelves, increment of

74 sedimentation input) which might be transmitted throughout the entire ecosystem.

75 Although FW studies use binary webs that indicate the presence of a trophic interaction but do

76 not provide any information on the frequency of the interaction or the rate of biomass flow

77 through the interaction, overlap graphs (e.g. competition and common-enemy graphs), can

78 provide information about indirect interaction strength between predators and prey, respectively.

79 Indirect effects in predator and prey assemblages can also be studied by evaluating these graphs.

80 The strength of predator-predator and prey-prey indirect interactions is extremely difficult to

81 measure but, if they prove generally prevalent, they could be a major driver of community

82 dynamics and ecosystem functioning (Woodward et al. 2005). The analysis of the degree

83 distribution of links in the overlap graphs, omitted in most FW studies, might be very useful to

84 identify, based on the competition graph, generalist and specialist predators, and to evaluate

85 energy pathways in the common-enemy graph.

86 In the current work, we present the first, detailed analysis of the FW for the Potter Cove

87 ecosystem (South Shetland Islands, Antarctica). The objectives of this study were to: 1) analyze

88 the complexity and structure of the ecological network in the context of the most-studied marine 
89 FWs; and 2) examine its degree distribution and overlap graphs in order to gain insight into the

90 ecosystem dynamics and functioning.

\section{2. Methods}

92 Potter Cove is a $4 \mathrm{~km}$ long and $2.5 \mathrm{~km}$ wide Antarctic fjord located at 25 de Mayo/King George

93 Island (62 $14^{`} \mathrm{~S}, 58^{\circ} 40^{`} \mathrm{~W}$, South Shetland Islands) (Fig. 1). A shallow sill (<30 m) separates its

94 inner and outer areas. The inner cove is characterized by soft sediments and by a shallower depth

95 than the outer cove $(<50 \mathrm{~m})$; in the outer cove the bottom is mainly rocky and with average

96 depths of $100 \mathrm{~m}$. Potter Cove is adjacent to Maxwell Bay, which connects to the Bransfield

97 Strait. Water circulation in Potter Cove is strongly influenced by the general circulation of

98 Maxwell Bay (Roese and Drabble 1998). A cyclonic circulation has been identified, with

99 efficient water renewal in the northern sector, where water from Maxwell Bay enters the Cove.

100 Freshwater input varies both seasonally and inter-annually and carries important amounts of

101 suspended sediments. Two main creeks discharge into the Cove, the Matias and the Potter

102 creeks. They exhibit different regimes, the first being snowy and lacustrine, the latter snowy and

103 glacial (Varela 1998). Drainage ranged between 0.03 and $0.11 \mathrm{~m}^{3} \mathrm{~s}^{-1}$ in the Matias Creek and

104 from 0.08 to $3.8 \mathrm{~m}^{3} \mathrm{~s}^{-1}$ in Potter Creek (Varela 1998). Suspended sediment discharges ranged

105 between 0.04 and $15 \mathrm{~kg} \mathrm{~m}^{-3}$ (average $=0.14 \mathrm{~kg} \mathrm{~m}^{3}$ ), which correlate with air temperature. These

106 characteristics are consistent with data from other glaciomarine environments in Antarctic

107 coastal waters (Leventer and Dunbar 1985). 


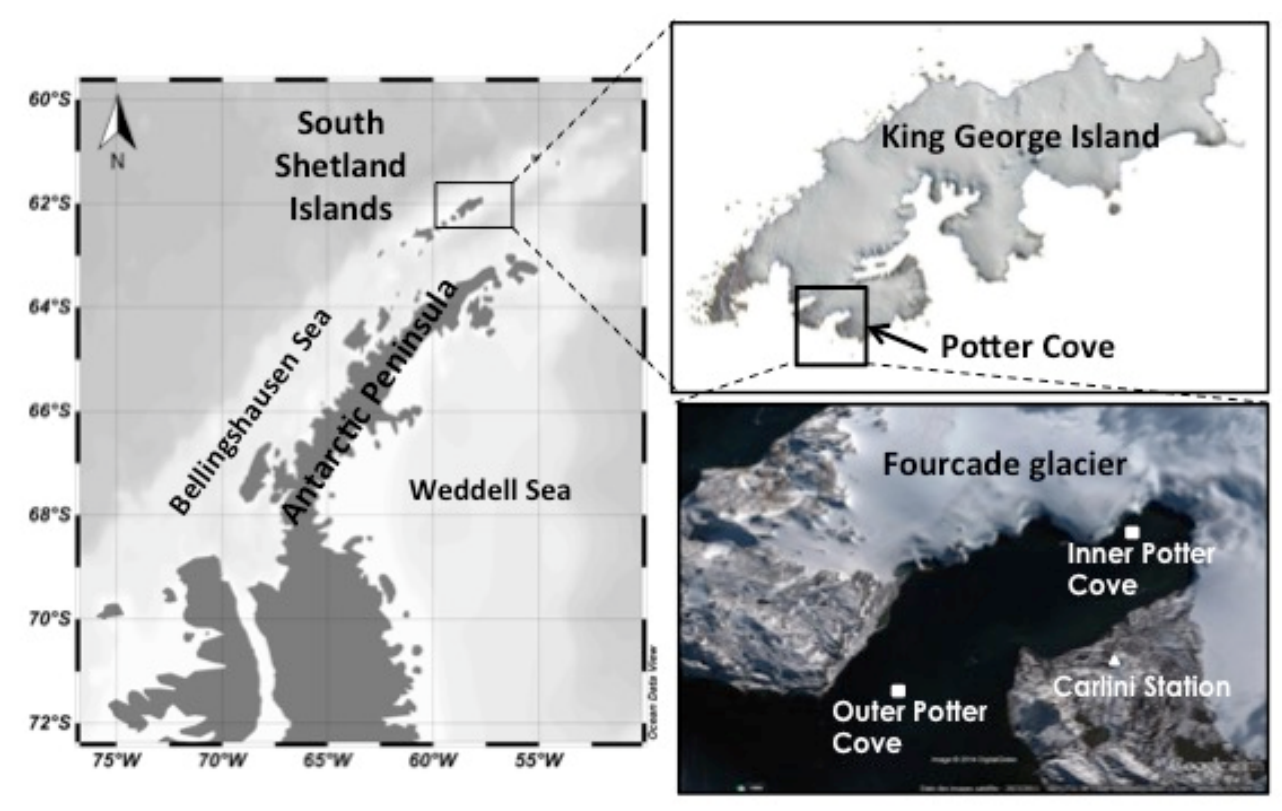

108 Fig. 1. Map of Potter Cove and its location on Isla 25 de Mayo/King George Island.

\section{2.1. Food web assembly}

110 We constructed the FW of Potter Cove ecosystem primarily based on information about species

111 living in that system and their feeding habits from studies within the framework of an

112 international research cooperation between Argentina and Germany initiated in 1994 and

113 ongoing for more than 20 years (Wiencke et al. 1998, 2008).

114 We collected information on feeding links by a thorough literature search $(>500$ papers and

115 reports revised). To assemble the network we only considered trophic interactions confirmed by

116 gut content studies and/or field observation. Furthermore, direct observations of researchers from

117 field sampling campaigns in the Cove (e.g. divers when collecting benthic samples) were also

118 taken into account. Laboratory experimental studies, where feeding selectivity, palatability or

119 behavior was tested, were not included in this study as we consider the trophic links proved from

120 experiments are not as robust as the ones gathered from the field data. Investigations using

121 biomarkers (i.e. stable isotopes and fatty acids) were not considered since trophic interactions are 
122 established by sampling few individuals $(\mathrm{n} \approx 10-100)$ and studied prey-predator relationships are

123 usually between trophic species widely aggregated. Further details on the trophic links included

124 in the present study (references and methods used to confirm a link) are presented in the

125 electronic supplementary material (Appendix A).

126 Trophospecies, here defined as aggregated groups of taxa, were only considered when data on

127 specific biological species were not available (lack of data resolution) or when taxa shared the

128 same set of predators and prey within the FW (trophic similarity criteria). We have not

129 considered top vertebrate predators (e.g. penguins, seals, whales), as they only sporadically enter

130 the Cove to feed. In addition, pelagic fish (typically taken by Antarctic penguins and pinnipeds)

131 were not considered due to paucity of ocurrence (Barrera-Oro and Casaux 2008).

132 The diversity of the expertise of the authors contributing to the present study was a key factor in

133 generating the quality of the FW, and inherently improved the network representation of the

134 Potter Cove ecosystem.

135 2.2. Network analysis

136 An interaction matrix of pairwise interactions was constructed; a value of 1 or 0 was assigned to

137 each element $a_{i j}$ of the matrix depending on whether the $j$-species preyed or not on the $i$-species.

138 The FW is an oriented graph with $L$ trophic links between $S$ nodes or species. The FW graph was

139 drawn from the interaction matrix using Visone software version 2.9.2 (Brandes and Wagner

140 2004).

141 Several network properties that are commonly used to describe complexity and structure in FWs

142 were calculated (Dunne et al. 2002b, de Santana et al. 2013): (1) number of species, $S$; (2) total

143 number of interactions or trophic links, $L$; (3) number of interactions per species or linkage 
144 density, $L / S$; (4) connectance or trophic links divided by total number of possible interactions,

$145 C=L / S^{2}$; percentage of (5) top species (species with prey but without predators), (6) intermediate

146 species (species with prey and predators), (7) basal species (species with predators/consumers

147 but without prey); and (8) percentage of omnivores (species eating prey from more than one

148 trophic level).

149 Trophic levels $(T L)$ of species were calculated using the short-weighted $T L$ formula of Williams

150 and Martinez (2004). Short-weighted trophic level is defined as the average of the shortest $T L$

151 and prey-averaged $T L$. Shortest $T L$ of a consumer in a food web is equal to $1+$ the shortest chain

152 length from this consumer to any basal species (Williams and Martinez 2004). Prey averaged TL

153 is equal to $1+$ the mean $T L$ of all consumer's trophic resources, calculated as

$$
T L j=1+\sum_{i=1}^{S} l i j \frac{T L i}{n j}
$$

154 where $T L_{j}$ is the trophic level of species $j ; \mathrm{S}$ is the total number of species in the food web; $l_{i j}$ is

155 the connection matrix with $S$ rows and $S$ columns, in which for column $j$ and row $i, l_{i j}$ is 1 if

156 species $j$ consumes species $i$ and 0 if not; and $\mathrm{n}_{j}$ is the number of prey species in the diet of

157 species $j$. Therefore, Short-weighted $T L$ yields a minimum estimate of $T L$ and assumes a value of

1581.0 for basal species (Williams and Martinez 2004). We considered the mean $T L$ of the web as

159 the average of all species' $T L$.

160 Two secondary graphs, the competition graph and the common-enemy graph, were constructed.

161 The first one, also known as predator overlap graph, connects predators that share one or more

162 prey, while the latter is drawn by connecting prey species sharing one or more predators (Pimm

163 et al. 1991). Predator overlap graph results were discussed considering dietary data on each

164 predator species involved. To examine a plausible organization in predator and prey species, we 165 separately studied the degree distribution of links $P(k)$ for each overlap graph. Links in predator 
166 distribution represent the number of prey, while in prey distribution it depicts number of

167 predators. Graphs were plotted using Visone software (version 2.9.2).

168 We also studied the topology of the FW by measuring three more properties: (9) characteristic

169 path length (ChPath), or the average shortest path length between all pairs of species, (10)

170 clustering coefficient (CC), or the average fraction of pairs of species connected to the same

171 species that are also connected to each other, and (11) degree distribution, or the fraction of

172 trophic species $\mathrm{P}(k)$ that have $k$ or more trophic links (both predator and prey links) (Albert and

173 Barabási 2002). Trophic links were treated as undirected when calculating path length and

174 clustering because effects can propagate through the web in either direction, through changes to

175 both predator and prey species (Watts and Strogatz 1998).

176 Results of these properties and the ones aforementioned for Potter Cove FW were compared

177 among other marine webs that were chosen considering different criteria: size $(\mathrm{S}>25)$, temporal

178 era (fourth era, see Link et al. 2005) and quality data (i.e. FWs built upon stable isotopes were

179 excluded).

180 Degree distributions of the total FW and of the mentioned overlap graphs were examined and

181 fitted using nonlinear regression analysis (Xiao et al. 2011). Model selection was performed by

182 computing the Akaike Information Criterion corrected for small sample size (AICc) (Burnham

183 and Anderson 2002, Xiao et al. 2010). R package $n l s$ (Nonlinear Least Squares) was used to

184 make power-law and exponential fitting (R Core Team 2016). 


\section{Results}

186 The Potter Cove FW (Fig. 2) includes 91 species, composed of 71 biological species, 17

187 trophospecies (i.e., merging two or more taxonomic species by trophic similarity) and 3 non-

188 living nodes (i.e. fresh detritus, aged detritus and necromass).

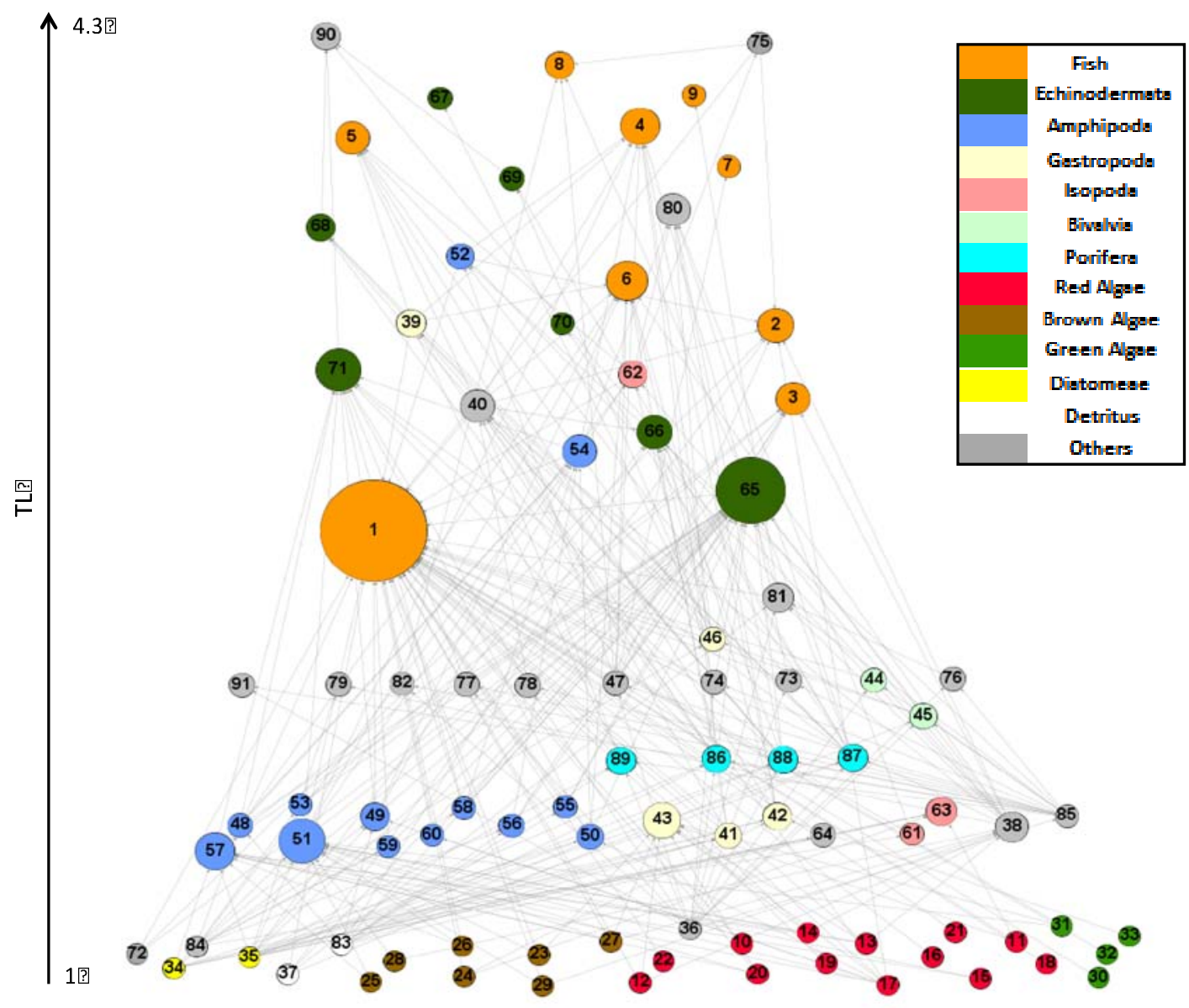

189 Fig. 2. Graphic representation of Potter Cove FW with the trophic level (TL) on the vertical scale and node width proportional to the total degree (in- and out-). Node colors are by functional group. Network was plotted with Visone (version 2.9.2). See electronic supplementary material (Appendix B) for exhaustive lists of trophic species, their trophic level, degree (in- and outlinks), functional and taxonomic group affiliation (e.g. algae, phytoplankton, zooplankton, fish, 194 amphipods).

195 Algae (24 species) comprise red (13 spp.), brown (7 spp.) and green algae (4 spp.). The next

196 trophic levels consist of 13 amphipod species, 3 isopod species, 4 sponge species (one 
197 aggregated node: Stylocordyla borealis and Mycale acerata), 5 gastropod species, 2 bivalve

198 species, 7 echinoderm species, and 9 demersal fish species. See electronic supplementary

199 material (Appendix B) for exhaustive lists of taxa, their trophic level, degree (in- and out-links),

200 functional and taxonomic group affiliation (e.g. algae, phytoplankton, zooplankton, fish,

201 amphipods).

202 The first thing to note about Potter Cove FW is that most of the species (47\%) were at

203 intermediate levels, implying that they act as predators and prey depending on the trophic

204 interaction they are involved in. Moreover, as shown in Fig. 2 some species are far more

205 connected ( 9 species with degree $>15$ ) than others, according to the total number of trophic

206 interactions they have (e.g. fish and echinoderms).

207 The main properties of the network complexity for Potter Cove FW included 307 total

208 interactions and a linkage density of 3.4. As a consequence, a connectance of 0.04 was reported

209 (Table 1).

210 Table 1. Properties of network complexity and structure for Potter Cove FW. S = number of

211 trophic species, $\mathrm{L} / \mathrm{S}=$ linkage density, $\mathrm{C}=$ connectance $\left(\mathrm{L} / \mathrm{S}^{2}\right), \mathrm{T}=\%$ top species, $\mathrm{I}=\%$

212 intermediate species, $\mathrm{B}=\%$ basal species, $\mathrm{Omn}=$ percentage of omnivorous, $\mathrm{TL}=$ mean trophic

213 level, $\mathrm{ChPath}=$ characteristic path length, $\mathrm{CC}=$ clustering coefficient.

\begin{tabular}{lcccccccccc}
\hline Food web & $\mathrm{S}$ & $\mathrm{L} / \mathrm{S}$ & $\mathrm{C}$ & $\mathrm{T}$ & $\mathrm{I}$ & $\mathrm{B}$ & Omn & TL & ChPath & CC \\
\hline Potter Cove & 91 & 3.4 & 0.04 & 19 & 47 & 34 & 45 & 2.1 & 1.8 & 0.08 \\
\hline
\end{tabular}

214 Although intermediate species outnumbered top and basal species, comprising more than half of

215 the species in the FW, the basal species were also numerous (Table 1). In addition, almost half of

216 the species were omnivorous (45\%), similar to the percentage observed in intermediate species.

217 The mean trophic level (TL) for Potter Cove FW was 2.1, which was supported by the relatively

218 high proportion of basal species that tend to lower the average. 
219 Network topological properties, characteristic path length (ChPath) and clustering coefficient

220 (CC) were 1.8 and 0.08 , respectively.

221 The degree distribution for the Potter Cove FW (Fig. 3) showed that the exponential model best

222 fitted the data, according to nonlinear regression and AICc analyses (Table 2). The three species

223 with the highest degree were: Notothenia coriiceps (fish, 48 links), Ophionotus victoriae

224 (echinoderm, 33 links) and Gondogeneia antarctica (amphipod, 20 links).

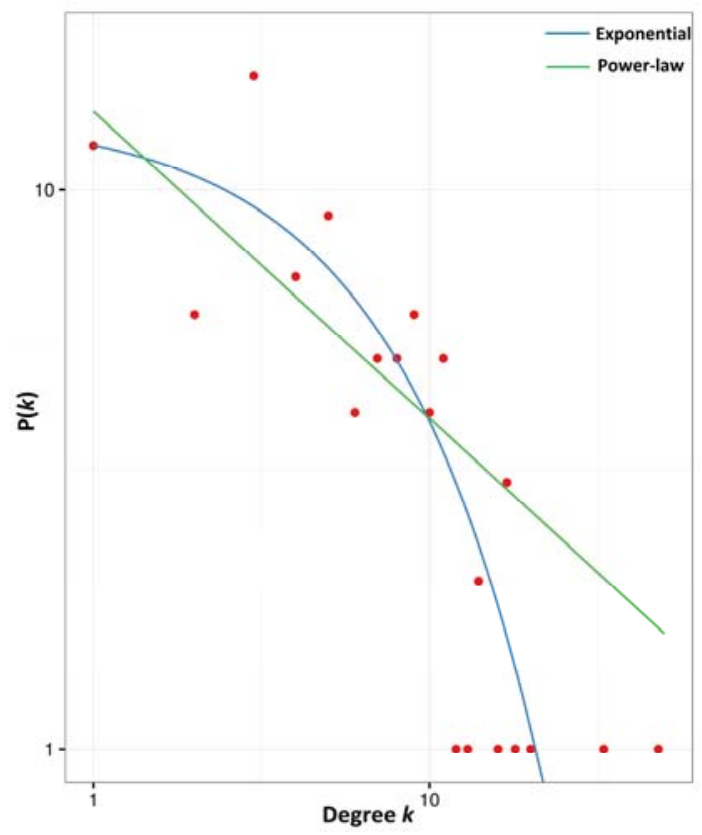

225 Fig. 3. Log-log degree distribution of links $P(k)$ for Potter Cove FW. Two candidate models are 226 shown. Best fit is the exponential model.

227 The competition graph derived from Potter Cove FW is highly connected. It includes 60 species

228 and 478 indirect interactions (Fig. 4) and shows that several pairs of predators share many prey.

229 For instance, all trophic species of sponges form a more connected group than with the rest of the

230 prey species. Furthermore, some species of echinoderms, amphipods and demersal fish are

231 intensively competing for common food sources (see link width and color, Fig. 4). 


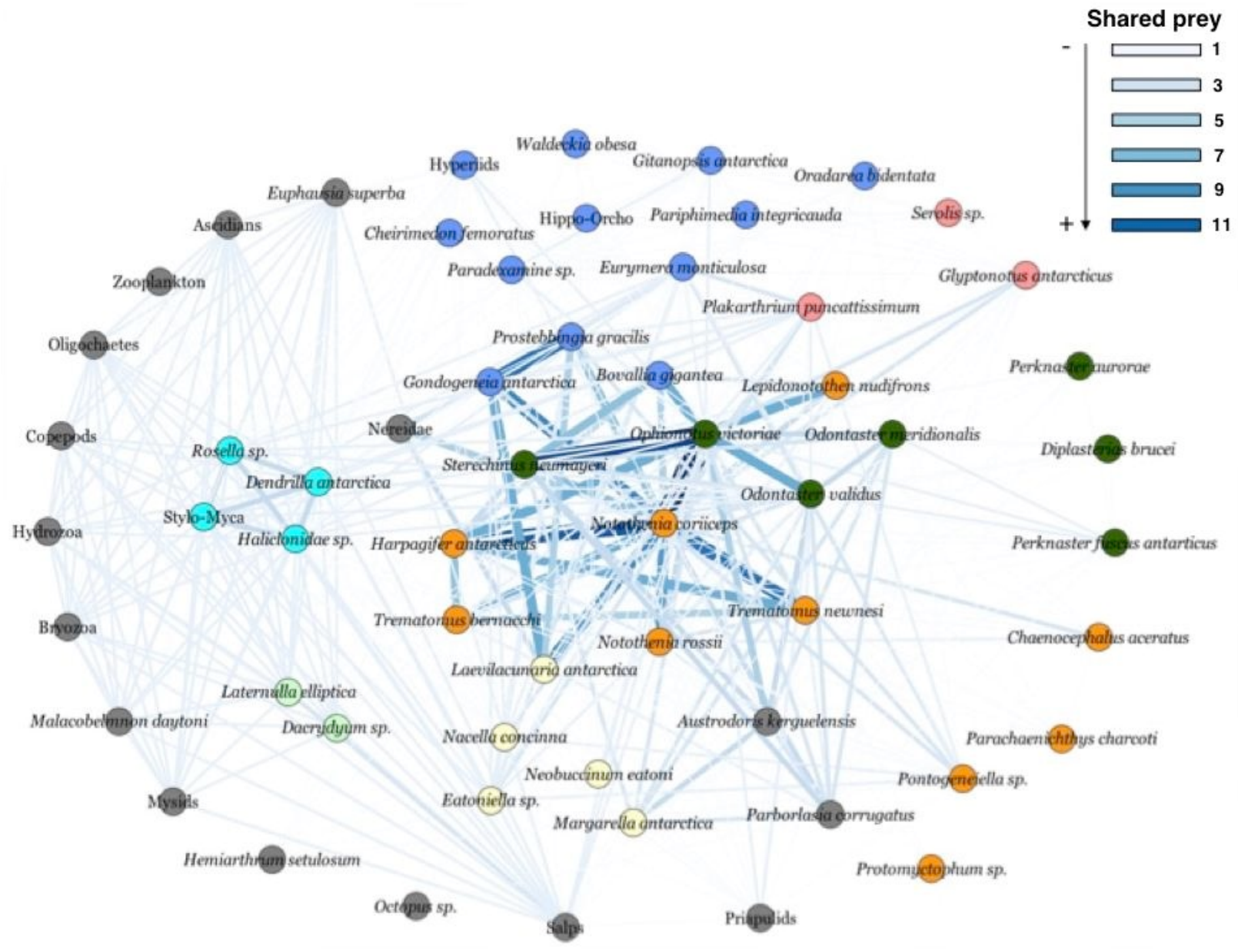

232 Fig. 4. Competition graph for the Potter Cove FW. Node colors (as in Fig. 2): functional groups. 233 Link width and colors: number of shared prey.

234 To study these potential species interactions, specific competition graphs for the latter two

235 functional groups were built (Fig. 5). The fish overlap graph includes 9 biological species and 28

236 competitive interactions. It is worthy to note that two species, Notothenia coriiceps and

237 Harpagifer antarcticus, presented highly overlapping diets. Moreover, $N$. coriiceps shares many

238 of the same prey species, which may or may not involve any competition (Fig. 5 a). On the other

239 hand, the amphipod overlap graph suggested low resource overlap among species. However,

240 Gondogeneia antarctica and Prostebbingia gracilis have many prey in common (Fig. 5 b). 
(a)

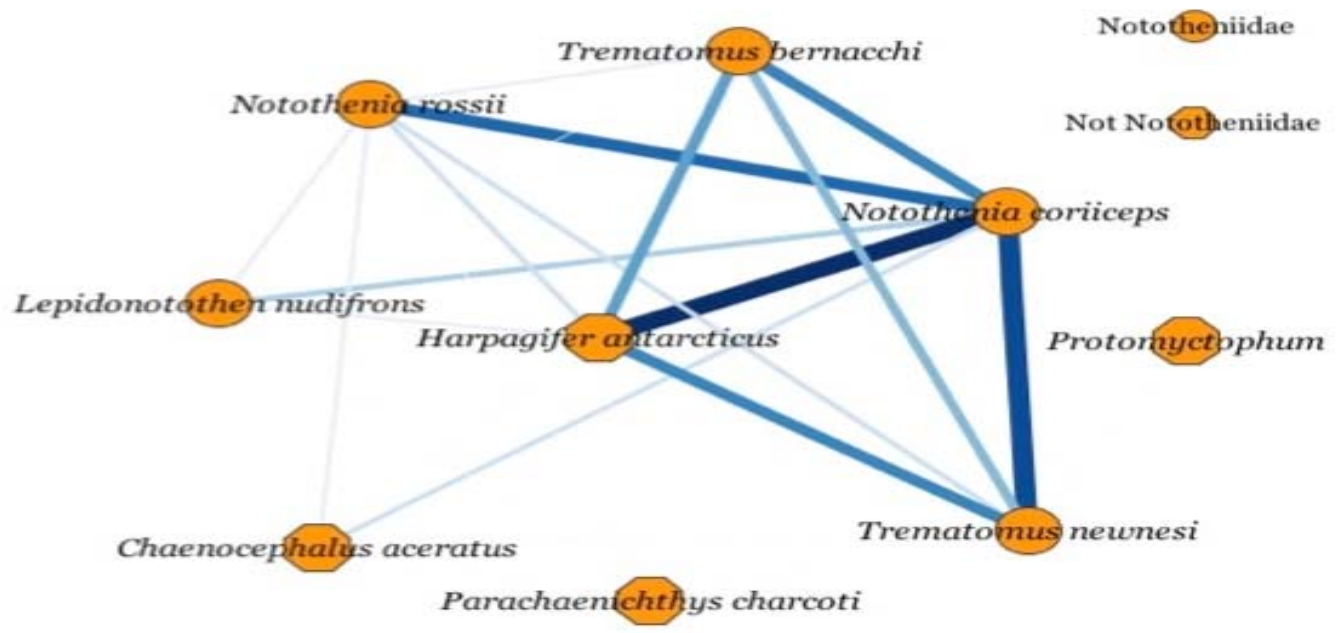

(b)

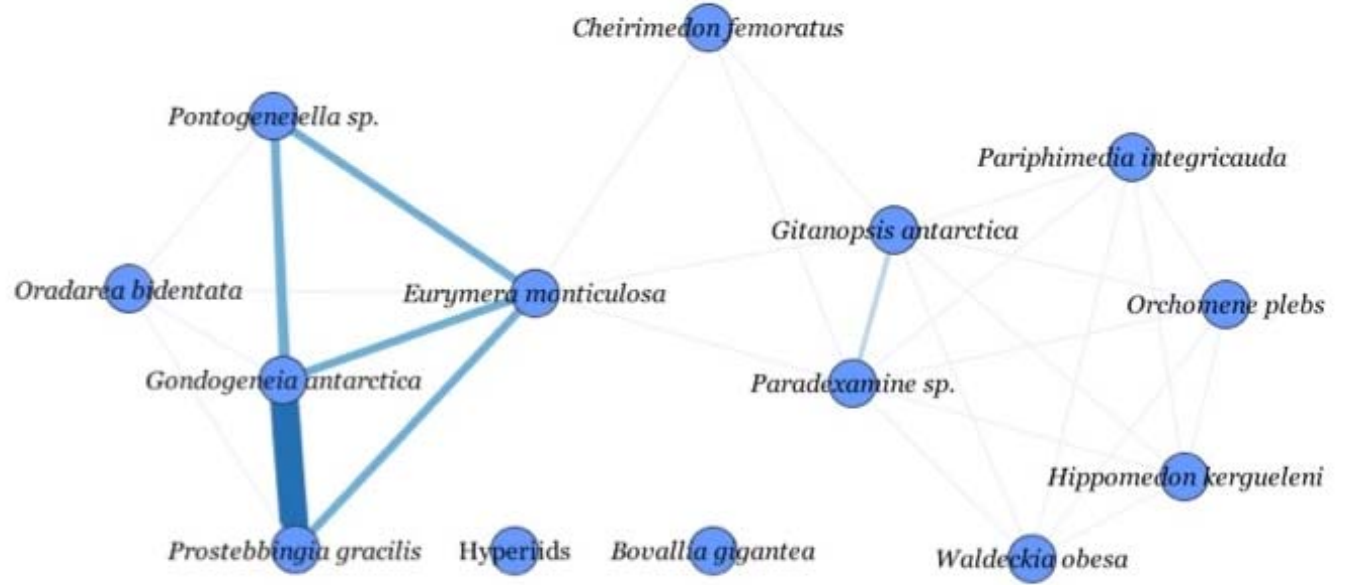

241 Fig. 5. Competition graphs for (a) demersal fish and (b) amphipod functional groups. Link width and colors: number of shared prey (see Fig. 4).

243 The common-enemy graph shows a hyperconnected structure, where the majority of the species

244 are connected. It contained 74 prey species and 1497 indirect interactions (Fig. 6, up-left). Most

245 of the species are connected due to having only one predator in common. In order to elucidate

246 groups of species having stronger indirect interactions, we eliminated links with value 1 . This

247 new graph (Fig. 6, large network) showed groups of species connected by strong interactions: 
248 sponges (except for Dendrilla antarctica), benthic diatoms - fresh detritus, benthic diatoms -

249 epiphytic diatoms, zooplankton - phytoplankton, some species of amphipods (i.e. Gondogeneia

250 antarctica - Paradexamine sp. - Prostebbingia sp. - Eurymera meticulosa), and several red and

251 brown algae (Gigartina skottsbergii-Desmarestia menziesii - Iridaea cordata) (Fig. 6).

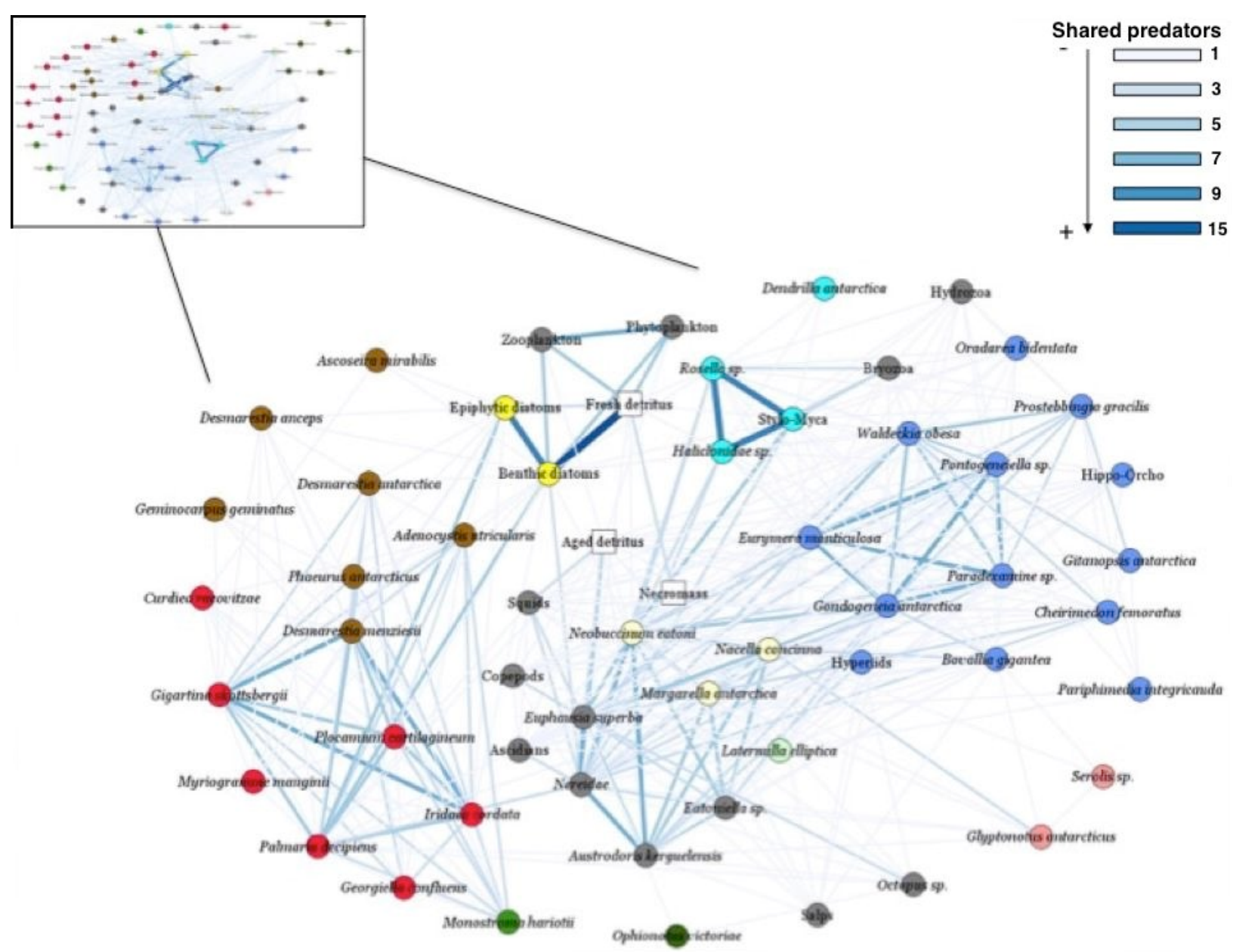

252 Fig. 6. Common-enemy graph for Potter Cove FW. Original graph in left upper corner. Large

253 network shows prey species that share more than one predator. Node colors (as in Fig. 2):

254 functional groups. Link width and colors: number of shared predators.

255 Degree distribution of links in the competition and common-enemy graphs (Fig. 7) fit best to an 
(a)

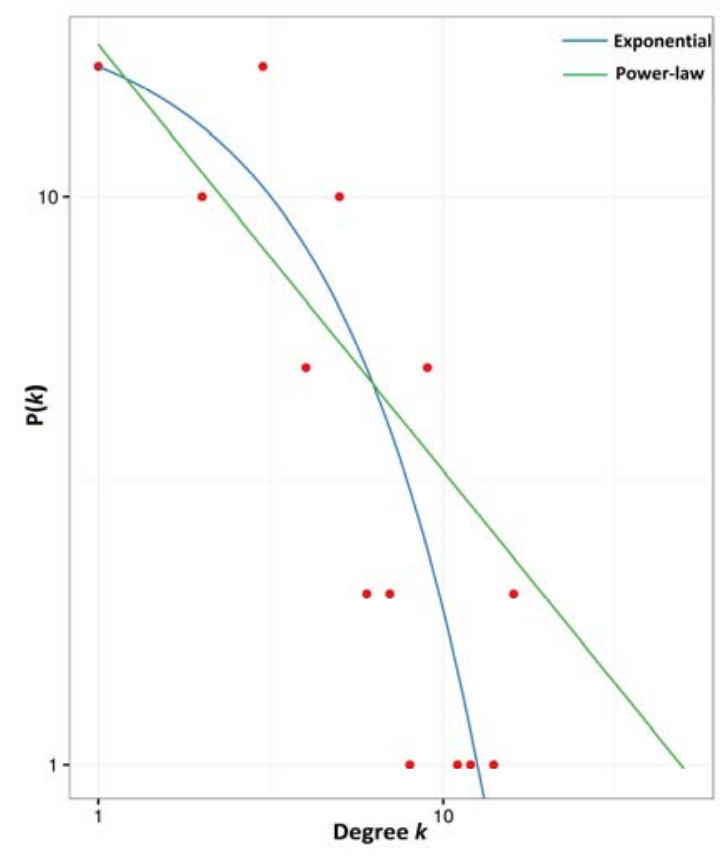

(b)

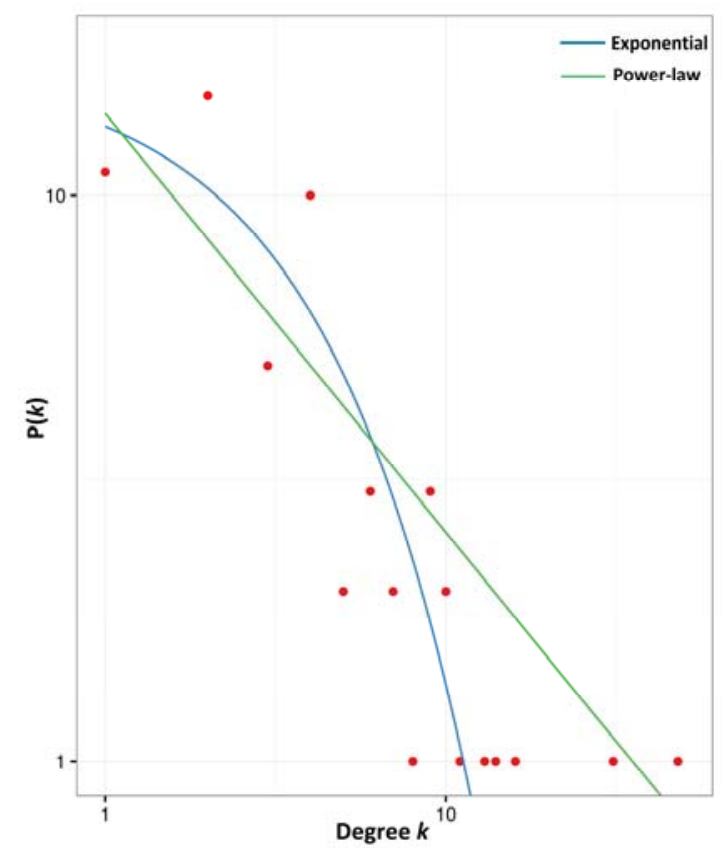

257 Fig. 7. Log-log degree distribution of links $P(k)$ for (a) the competition and (b) common-enemy 258 graphs. Best fit is the exponential model for both distributions.

260 Comparison between the Potter Cove FW and other marine webs showed that linkage density

$261(L / S)$ and connectance $(C)$ were lower in the Potter Cove web. The proportions of top and basal

262 species were relatively high, whereas the percentage of omnivory was the second lowest among

263 all webs that were compared. While the characteristic path length in Potter Cove FW was similar

264 to the rest of the FWs, the clustering coefficient was one order of magnitude lower (Table 3). 
265 Table 2. Model fit of exponential and power-law models for degree distributions of total FW (in-

266 and out-links), competition (only predators) and common-enemy (only prey) overlap graphs.

267 AICc and $\mathrm{AIC}_{\Delta}$ are the Akaike corrected for small sample size and delta values for each

268 candidate model. * Indicates best-fit model.

\begin{tabular}{llll}
\hline & Model & AICc & $\mathbf{A I C}_{\boldsymbol{\Delta}}$ \\
\hline Total FW & Exponential * & 94.90 & 0.000 \\
& Power-law & 101.70 & 6.756 \\
\hline Competition graph & Exponential * & 72.56 & 0.000 \\
& Power-law & 76.31 & 3.751 \\
\hline Common-enemy graph & Exponential * & 76.16 & 0.000 \\
& Power-law & 82.00 & 5.839 \\
\hline
\end{tabular}

269 Table 3. Comparison of network properties between Potter Cove and other marine FWs. S = 270 number of trophic species, $\mathrm{L} / \mathrm{S}=$ linkage density, $\mathrm{C}=$ connectance $\left(\mathrm{L} / \mathrm{S}^{2}\right), \mathrm{T}=\%$ top species, $\mathrm{I}=$

$271 \%$ intermediate species, $\mathrm{B}=\%$ basal species, Omn = percentage of omnivorous, $\mathrm{TL}=$ mean

272 trophic level, ChPath = characteristic path length, $\mathrm{CC}=$ clustering coefficient. NA: not available 273 data.

\begin{tabular}{|c|c|c|c|c|c|c|c|c|c|c|c|}
\hline Food web & $S$ & $L / S$ & $C$ & $T$ & $I$ & $B$ & $O m n$ & $T L$ & ChPath & $C C$ & Source \\
\hline \multicolumn{12}{|c|}{ Marine non-polar webs } \\
\hline Car. reef (s) & 50 & 11.1 & 0.22 & 0 & 94 & 6 & 86 & 2.9 & 1.6 & 0.36 & Opitz (1996) \\
\hline Benguela & 29 & 7.0 & 0.24 & 0 & 93 & 7 & 76 & 3.2 & 1.6 & 0.30 & $\begin{array}{l}\text { Yodzis } \\
(1998)\end{array}$ \\
\hline NE US Shelf & 79 & 17.8 & 0.22 & 4 & 94 & 3 & 62 & 3.1 & 1.6 & 0.31 & Link (2002) \\
\hline Carib. (1) & 249 & 13.3 & 0.05 & NA & NA & NA & NA & NA & 1.9 & 0.16 & $\begin{array}{l}\text { Rezende et } \\
\text { al. (2009) }\end{array}$ \\
\hline Lough Hyne & 350 & 14.7 & 0.04 & NA & NA & NA & NA & NA & NA & NA & $\begin{array}{l}\text { Riede et al. } \\
2010\end{array}$ \\
\hline \multicolumn{12}{|c|}{ Marine polar webs } \\
\hline Arctic I & 140 & 6.8 & 0.05 & 40 & 56 & 14 & 80.7 & 2.3 & NA & NA & $\begin{array}{l}\text { Bodini et al. } \\
(2009)\end{array}$ \\
\hline Arctic II & 159 & 8.6 & 0.05 & NA & NA & NA & 52 & 2.7 & 2.3 & 0.25 & $\begin{array}{l}\text { Kortsch et al. } \\
2015\end{array}$ \\
\hline Antarctic & 586 & 6.8 & 0.01 & 23 & 21 & 56 & 41.1 & 2.2 & 3.0 & 0.14 & $\begin{array}{l}\text { de Santana et } \\
\text { al. }(2013)\end{array}$ \\
\hline Weddell Sea & 491 & 33.2 & 0.07 & 6.5 & 80 & 13.5 & 67 & 2.5 & NA & NA & Jacob (2005) \\
\hline Potter Cove & 91 & 3.4 & 0.04 & 19 & 47 & 34 & 45 & 2.1 & 1.8 & 0.08 & This study \\
\hline
\end{tabular}




\section{4. Discussion}

275 4.1. Food web complexity and structure

276 Potter Cove FW properties of complexity and structure showed several singularities that make

277 the web unique in terms of species-richness, link configuration and topological characteristics.

278 Network complexity was mainly assessed by linkage density (L/S) and connectance (C). Both of

279 these properties were found to be relatively low in the Potter Cove web: $\mathrm{L} / \mathrm{S}=3.4$ and $C=0.04$.

280 Nevertheless, direct comparisons of linkage density and connectance values suggest that marine

281 FWs tend to resemble each other, and that they are fundamentally different from other kinds of

282 FWs, based on their high values (Dunne et al. 2004). Opposite to this hypothesis of marine FW

283 similarity, de Santana et al. (2013) found that connectance in the Arctic marine FW was 5 times

284 larger than that of the Antarctic one (0.05 versus 0.01). Furthermore, within marine webs, polar

285 networks tend to display low values of linkage density (de Santana et al. 2013). In this sense,

286 complexity exhibited in the Potter Cove FW resembles closely to what is known so for FWs in

287 Polar regions.

288 Could low values of linkage density and connectance in Potter Cove network be a consequence

289 of methodological issues? Dunne et al. (2002b) suggested that both low- and high-connectance

290 FWs are unusual, and that extreme connectances may sometimes be artifacts of assembly

291 procedures. They exemplified this statement by showing that the lowest connectance webs they

292 studied ( $C \approx 0.03$, Grassland and Scotch Broom), which is similar to Potter Cove FW

293 connectance value, are "source-webs". These are constructed by linking food chains upward

294 starting from one or a few basal species. The Potter Cove FW is a species-rich ecological

295 network and not a source-web since it was not constructed upward from one or two basal species

296 but it is characterized by $>30 \%$ basal species. Thus there is no evidence we know of which 
297 suggests that our low values of linkage density and connectance were a consequence of the

298 assembly procedure of the network. In turn this implies that the assembly-connectance

299 relationship in FWs is not as strong as previously thought (Dunne et al. 2002b).

300 Whether ecological networks display low or high L/S and C values is crucial to gain insight in

301 the ecosystem's synthetic properties like robustness. Empirical analyses of FWs support the

302 notion that the robustness of a FW increases with its linkage density and connectance (De

303 Angelis 1975, Dunne et al. 2002a, Montoya and Solé 2003). Low values of L/S and C found in

304 Potter Cove FW, combined with ongoing climate change effects on benthic communities in the

305 area (Pasotti et al. 2015b, Sahade et al. 2015), suggest potential ecosystem fragility which need

306 to be addressed.

307 Furthermore, direct comparison of common FW properties, like percentages of top, intermediate

308 and basal species, indicates that the Potter Cove network has strong structural differences and

309 shows unique features compared to other marine ecosystems. Important dissimilarities were

310 found in top and basal species values as Potter Cove FW shows a higher number of these trophic

311 species. After comparing 19 FW properties, Dunne et al. (2004) concluded that the excessively

312 low percentage of basal taxa in marine FWs compared to other systems is clearly an artifact of

313 poor resolution of primary producers and consumer links to them. One of the methodological

314 strengths of Potter Cove FW is the high taxonomic resolution of the basal nodes. A good

315 taxonomic resolution of the lower trophic levels, such as the macroalgal community, is essential

316 to understand Potter Cove ecosystem functioning, since there seems to be a species-specific

317 selective consumption (Barrera-Oro and Casaux 1990, Iken et al. 1997, Iken et al. 1998).

318 Furthermore, algal species show a marked pattern of depth distribution and tridimensional

319 structure (Quartino et al. 2005, Huang et al. 2007). Macroalgae are one of the main primary 
320 producers in Potter Cove, and probably support a large fraction of secondary production of the

321 benthos community (Quartino et al. 2008). Implications in ecosystem functioning and stability

322 are only possible to elucidate in FWs where species involved in energy and matter transfer

323 processes are well represented.

324 Proportions of intermediate species (I) and omnivory (Omn) in Potter Cove FW are relatively

325 low when compared to other marine webs, but close to values for Antarctic FW as reported by de

326 Santana et al. (2013). Levels of $I$ and omnivory are usually correlated in FW studies, as the

327 majority of species acting as predators and prey also feed on more than one trophic level

328 (omnivorous). The importance of omnivory for the structure and dynamics of FWs is a long-

329 standing controversy in ecology (Burns 1989, Polis 1991), and whether omnivory stabilizes or

330 destabilizes webs is not clear (Vandermeer 2006, Namba et al. 2008, Johnson et al. 2014). In

331 Antarctica a recent study suggests that omnivory is a beneficial trait as it allows for more

332 responsive and flexible utilization of food sources that may be temporally and spatially

333 constrained and unpredictable (Norkko et al. 2007). The omnivory reported here for Potter Cove

334 FW is the second lowest percentage among marine webs included in the present study, would

335 suggest a low stability for Potter Cove FW. Additionally, this result generates testable

336 hypotheses about the probable stabilizing role of omnivory in large communities, since it was

337 proven that the risk of secondary extinctions after primary loss of species depends on the trophic

338 position of the extinct species (Borrvall et al. 2000) and the diversity of that trophic level

339 (insurance hypothesis, Yachi and Loreau 1999).

340 The mean trophic level for this FW (2.1) is also relatively low, which is the result of several

341 singularities of the Potter Cove ecological network. Firstly, as already mentioned, the number of

342 basal trophic species is high, exceeding $30 \%$ of number of species (diversity). What's more, the 
343 maximum trophic level was 4.27, lower than most other FWs studied (Dunne et al. 2002b, 2004),

344 which implies that top and basal species are separated by few intermediate taxa. It is worthy to

345 clarify here that Antarctic top predators, e.g. marine mammals, might increase maximum trophic

346 level of the web but were not included as they are rarely reported in the Cove. Therefore, the

347 transfers of energy or nutrients from the base to the top of Potter Cove FW is small, so that the

348 number of times chemical energy is transformed from a consumer's diet into a consumer's

349 biomass along the FW is also small. Another reason why the mean trophic level is low is the fact

350 that most predators at intermediate levels (e.g. amphipods, isopods, bivalves, $N$. coriiceps) feed

351 predominantly on algae species and/or detritus, being mainly the product of dead and

352 decomposed macroalgae in Potter Cove (Iken et al. 1998, Huang et al. 2006, Quartino et al.

353 2008). The macroalgal detritus decomposes and is eaten by detritivores and suspensivores (e.g.

354 sponges, ascidians, bryozoans, cnidarians), supporting an important amount of the secondary

355 production (Tatián et al. 2004). The obtained low mean trophic level for Potter Cove FW clearly

356 shows what species-specific and/or community studies have suggested. These characteristics of

357 ecological communities have a high impact on ecosystem functioning, such as nutrient and

358 carbon cycling, and trophic cascades (Post 2002).

359 Short characteristic path length for Potter Cove FW ( $\approx$ two degrees of separation) is similar to

360 lengths found in other marine FWs. The length between pairs of species within marine webs is

361 low ( $\approx 1.6$ links) compared to other types of FWs, with values ranging from 1.3 to 3.7 (Dunne et

362 al. 2002b). This suggests that most species in Potter Cove FW are potentially very close

363 neighbours, and that negative effects could spread rapidly and widely throughout the web

364 (Dunne et al. 2002a). 
365 Additionally, the clustering coefficient in this web (0.08) was an order of magnitude lower than

366 those reported for other marine FWs (Link 2002, Dunne et al. 2004). A low coefficient indicates

367 that most species are similarly connected to each other, i.e. there are no densely sub-groups of

368 species interacting with one other. Particularly, the clustering coefficient result of Potter Cove

369 FW might be the consequence of hubs (i.e. species with high degree, $>20$ links) connected with

370 most of the species across the web and not with a specific group of species. The most connected

371 species, $N$. coriiceps (demersal fish) and Ophionotus victoriae (brittle star), have the widest

372 ecological niches in our study, being generalists and omnivores. By feeding across several

373 trophic levels and transversely in the FW, these species have a strong effect on clustering.

374 Specifically, $N$. coriiceps probably represents a keystone species in the bentho-pelagic coupling

375 process promoting the transfer of matter and energy between habitats (Barrera-Oro and Casaux

376 2008). At the same time, these hub species might be essential for understanding the spread of

377 perturbations (i.e. biodiversity loss) through the entire FW network.

378 4.2. Degree distribution and overlap graphs: implications for ecosystem

379 functioning

380 Webs with low connectance $(C \approx 0.03)$, such as Potter Cove FW, are more likely to display

381 power law degree distributions (Dunnet et al. 2002a, Montoya and Solé 2002), consistent with

382 the small-world phenomenon. These are webs combining high clustering, like regular lattices and

383 short path length, like random graphs (Watts and Strogatz 1998). Therefore, the Potter Cove FW,

384 with a low estimated connectance $(C=0.04)$, should display a power law degree distribution.

385 However, it fits best to an exponential distribution according to the low clustering coefficient.

386 The existence of a universal functional form in the degree distribution of FWs is still under 
387 debate, though Stouffer et al. (2005) have shown that approximately exponential degree

388 distributions can be derived from two different models: nested-hierarchy and generalized

389 cascade.

390 The influence of the degree distribution on the vulnerability of complex networks against

391 random failures and intentional attacks has become well known since the work of Albert et al.

392 (2000). Considering this relationship between degree distribution and vulnerability, Potter Cove

393 FW would be highly fragile to the removal of the most connected species, but not as much as in

394 power law networks (Albert el al. 2000, Dunne et al. 2002a, Estrada 2007). Furthermore, de

395 Santana et al. (2013) suggested that less connected communities should be more sensitive to the

396 loss of basal species than complex communities because the consumers in simple communities

397 are dependent on only a few species and cannot survive their loss. Nevertheless, we hypothesize

398 that although Potter Cove FW shows low connectance, it will be robust against basal node

399 extinctions due to the high percentage of these trophic species.

400 In addition, degree distribution of links in the competition graph showed that most species have

401 limited diets, feeding exclusively on few prey, whereas few species feed on a large amount of

402 food-sources, usually being generalists. The graph suggests that several predator species have

403 high prey overlap and thus the potential to strongly interact and compete for common prey; this

404 is the case for sponges, demersal fish and amphipods. We focused the analysis on fish and

405 amphipods as they are known to play an important role on the Antarctic marine ecosystem

406 (Barrera-Oro and Casaux 1998, Momo et al. 1998, Barrera-Oro 2002, Huang et al. 2006). Fish

407 data reflects that there is dietary overlap between $N$. coriiceps and H. antarcticus on the one hand

408 and between Trematomus newnesi and N. rossii on the other hand. Most of the dietary

409 comparisons for demersal Antarctic fish communities have dealt with food overlap between fish 
410 species pairs (Barrera-Oro 2003). Dietary overlap index (“S” index of Linton et al. 1981)

411 between N. coriiceps and N. rossii in Potter Cove as estimated by Barrera-Oro (2003) was 55\%,

412 meaning that these species could compete for more than half of their food-sources. The same

413 study estimated the index for $N$. coriiceps $-T$. newnesi, being 18\%, and N. coriiceps $-H$.

414 antarcticus, being 19\%. Barrera-Oro (2003) concludes that there is no evidence of food

415 competition among the shallow cold-water fish communities in Potter Cove. Nevertheless, our

416 results show that $N$. coriiceps and $H$. antarcticus have many prey in common, with a high degree

417 of overlapping. However, due to the differences in mobility, habitat use and adult size between

418 these two species (total length: 45 and $13 \mathrm{~cm}$ respectively), competition is probably low (Casaux

419 1998, Barrera-Oro 2003). Although the first one is a generalist and the latter a specialist, both

420 species can be grouped in the same feeding category given that they are benthos feeders, eating

421 amphipods (e.g. Gondogeneia antarctica, Paradexamine sp., Prostebbingia sp., Eurymera

422 monticulosa), gastropods (e.g. Margarella antarctica, Nacella concinna, Eatoniella sp.,

423 Neobuccinum eatoni), polychaetes (e.g. Nereidae), and krill in summer (Euphausia superba).

424 On the other hand, the competition graph for amphipods exhibited low dietary overlap among

425 species. It is worth mentioning that hyperiids and Bovallia gigantea are not connected, which

426 indicates that they do not share food sources with any other amphipods, nor between themselves.

427 Hyperiids and B. gigantea are both carnivores, though the latter mainly feeds on other species of 428 amphipods, such as E. monticulosa, Prostebbingia sp. and G. antarctica (Richard 1977). On the

429 contrary, hyperiids principally eat planktonic prey, such as copepods (Pakhomov and

430 Perissinotto 1996). The most important result of the overlap graph is that species are separated

431 according to their feeding strategies: herbivores (P. gracilis, G. antarctica, O. bidentata and

432 Prostebbingia sp. - left of the graph), detritivores (C. femoratus and Paradexamine sp. - middle 
433 graph), and scavengers (W. obesa, H. kergueleni, O. plebs and P. integricauda - right of the

434 graph). This demonstrates the importance and utility of the analysis of competition graphs, in

435 order to better understand alternative energy pathways within apparent trophic guilds; analysis

436 that would be improved by adding information on each predator species (e.g. body size and

437 mass, niche specialization).

438 Common-enemy graph derived from Potter Cove FW showed a hyper-connected graph, which

439 implies that most prey species share at least one predator. The fact that the prey overlap graph of

440 this FW exhibited high connectivity and exponential distribution has implications for the

441 functioning of the ecosystem. High-connected prey in Potter Cove FW are: phytoplankton -

442 zooplankton, benthic diatoms - epiphytic diatoms, and fresh detritus - benthic diatoms. The

443 latter shows that several sources of food and alternative energy pathways exist in the Potter Cove

444 ecosystem: phytoplankton (Ahn et al. 1993), benthic microalgal production (Dayton et al. 1986,

445 Gilbert 1991), and horizontal advection of allochtonous food particles (Dunbar et al. 1989);

446 important sources of organic matter for marine organisms living in coastal Antarctic ecosystems.

447 In conclusion, comparison of FW properties revealed a particular combination of characteristics

448 for the Potter Cove ecological network: middle size $(S \approx 100)$ compared to other marine FWs,

449 low linkage density and connectance (with no evidence of being an artifact of resolution or

450 assembly procedure), low \%-omnivory, short path length and low clustering coefficient.

451 According to the overlap graphs and their degree distributions, and the consistency with field

452 observations and investigations, we suggest these analyses are useful tools to gain insight into

453 ecosystem functioning. What is more interesting, the common-enemy graph showed the

454 existence of alternative energy pathways consistent with field investigations in the Cove. As also 
455 suggested for East Antarctica FW (Gillies et al. 2012), carbon flow among the benthic fauna in

456 Potter Cove is complex, with multiple sources of carbon being utilized, which can be asserted

457 given the good basal resolution of our network.

458 From a network perspective, Potter Cove FW properties suggest fragility and potential trophic

459 cascade effects although multiple energy pathways might add robustness to the web. Our results

460 suggest that species with a high number of links (e.g. Notothenia corriceps, Ophionotus

461 victoriae, Gondogeneia antarctica) could be considered as keystone species for the robustness of

462 Potter Cove ecosystem.

\section{Acknowledgments}

464 This research was supported by Consejo Nacional de Investigaciones Científicas y Técnicas

465 (CONICET, Argentina), Universidad Nacional de General Sarmiento and Alfred Wegener

466 Institute for Polar and Marine Research (AWI, Germany). The work was partially funded by PIO

467 14420140100035CO CONICET Argentina and conducted in the frames of the EU research

468 network IMCONet funded by the Marie Curie Action IRSES (FP7 IRSES, Action No. 319718).

469 We thank Dave K.A. Barnes for constructive suggestions on language aspects, which helped us

470 to improve the manuscript.

\section{References}

472 1. Ahn, I.Y., Kang, J.S., Kang, J.S., 1993. Primary food sources for shallow-water benthic

473 fauna in Marian Cove, King George Island during an Austral Summer. Korean Journal of

$474 \quad$ Polar Research 4, 67-72. 
2. Albert, R. and Barabási, A.L., 2002. Statistical mechanics of complex networks. Reviews of Modern Physics 74, 47-97.

477 3. Albert, R., Jeong, H. and Barabási, A.L., 2000. Error and attack tolerance of complex 478 networks. Nature 406, 378-382.

479 4. Barrera-Oro, E.R., 2002. The role of fish in the Antarctic marine food web: differences 480 between inshore and offshore waters in the southern Scotia Arc and west Antarctic Peninsula. Antarctic Science 14, 293-309.

5. Barrera-Oro, E.R., 2003. Analysis of dietary overlap in Antarctic fish (Notothenioidei) from the South Shetland Islands: no evidence of food competition. Polar Biology 26, $631-637$.

6. Barrera Oro, E.R. and Casaux, R.J., 1990. Feeding selectivity in Notothenia neglecta, Nybelin, from Potter Cove, South Shetland Islands, Antarctica. Antarctic Science 2, $207-$ 273.

7. Barrera-Oro, E.R. and Casaux, R.J., 1998. Ecology of demersal fish species from Potter Cove. In: Wiencke, C., Ferreyra, G., Arntz, W., Rinaldi, C. (Eds.), The Potter Cove Coastal Ecosystem, Antarctica. Alfred-Wegener Institut (AWI), Bremerhaven, pp. 156167.

8. Barrera-Oro, E.R. and Casaux, R.J., 2008. General ecology of coastal fish from the South Shetland Island and west Antarctic Peninsula areas. In: Wiencke, C., Ferreyra, G.A., 
10. Bodini, A., Bellingeri, M., Allesina, S. and Bondavalli, C., 2009. Using food web dominator trees to catch secondary extinctions in action. Philosophical Transactions of the Royal Society of London B: Biological Sciences 364, 1725-1731. risk of cascading extinction in model food webs. Ecology Letters 3, 131-136. networks. In: Jünger, M., Mutzel, P. (Eds.), Graph Drawing Software. Springer-Verlag,

$504 \quad$ Berlin, pp. 321-340.

505 13. Brose, U. and Dunne, J.A., 2009. Modelling the dynamics of complex food webs. In: Verhoef, H.A., Morin, P.J. (Eds.), Community ecology: Processes, Models, and Applications. Oxford University Press, Oxford, pp. 37-44. practical information-theoretic approach. Springer-Verlag, New York, 485 pp.

510 15. Burns, T.P., 1989. Lindeman's contradiction and the trophic structure of ecosystems.

$511 \quad$ Ecology 70, 1355-1362.

512 16. Casaux, R.J., 1998. The contrasting diet of Harpagifer antarcticus (Notothenioidei, 513 Harpagiferidae) at two localities of the South Shetland Islands, Antarctica. Polar Biology $514 \quad 19,283-285$.

515 17. Dayton, P.K., Watson, D., Palmisano, A., Barry, J.P., Oliver, J. S. and Rivera, D., 1986. 516 Distribution patterns of benthic microalgal standing stock at McMurdo Sound, $517 \quad$ Antarctica. Polar Biology 6, 207-213.

518 18. De Angelis, D.L., 1975. Stability and connectance in food web models. Ecology 56, 238519243. 
520 19. de Santana, C.N., Rozenfeld, A.F., Marquet, P.A. and Duarte, C.M., 2013. Topological

521 properties of polar food webs. Marine Ecology Progress Series 474, 15-26.

522 20. Deregibus, D., Quartino, M.L., Campana, G.L., Momo, F.R., Wiencke, C. and Zacher,

523 K., 2016. Photosynthetic light requirements and vertical distribution of macroalgae in

524 newly ice-free areas in Potter Cove, South Shetland Islands, Antarctica. Polar Biology 39,

$525 \quad 153-166$.

526 21. Dunbar, R.B., Leventer, A.R. and Stockton, W.L., 1989. Biogenic sedimentation in

527 McMurdo Sound, Antarctica. Marine Geology 85, 155-179.

528 22. Dunne, J.A., Williams, R.J. and Martinez, N.D., 2002a. Network structure and

529 biodiversity loss in food webs: robustness increases with connectance. Ecology letters 5, $530 \quad 558-567$.

531 23. Dunne, J.A., Williams, R.J. and Martinez, N.D., 2002b. Food-web structure and network

532 theory: the role of connectance and size. Proceedings of the National Academy of

$533 \quad$ Sciences 99, 12917-12922.

534 24. Dunne, J.A., Williams, R.J. and Martinez, N.D., 2004. Network structure and robustness

535 of marine food webs. Marine Ecology Progress Series 273, 291-302.

536 25. Estrada, E., 2007. Food webs robustness to biodiversity loss: The roles of connectance,

537 expansibility and degree distribution. Journal of Theoretical Biology 244, 296-307.

538 26. Gilbert, N.S., 1991. Microphytobenthic seasonality in near-shore marine sediments at

539 Signy Island, South Orkney Islands, Antarctica. Estuarine, Coastal and Shelf Science 33,

$540 \quad 89-104$. 
27. Gillies, C.L., Stark, J.S., Johnstone, G.J. and Smith, S.D., 2012. Carbon flow and trophic structure of an Antarctic coastal benthic community as determined by $\delta 13 \mathrm{C}$ and $\delta 15 \mathrm{~N}$. Estuarine, Coastal and Shelf Science 97, 44-57. gammaridean amphipod abundance and species composition associated with dominant subtidal macroalgae from the western Antarctic Peninsula. Polar Biology 30, 1417-1430. rates of common Antarctic gammarid amphipods on ecologically important sympatric macroalgae. Journal of Experimental Marine Biology and Ecology 329, 55-65. the Antarctic fish Notothenia coriiceps: evidence for selective feeding on macroalgae. Antarctic Science 9, 386-391.

30. Iken, K., Quartino, M.L., Barrera Oro, E.R., Palermo, J., Wiencke, C. and Brey, T., 1998. Trophic relations between macroalgae and herbivores. In: Wiencke, C., Ferreyra, G., Arntz, W., Rinaldi, C. (Eds.), The Potter Cove Coastal Ecosystem, Antarctica. AlfredWegener Institut (AWI), Bremerhaven, pp. 258-262. 
562 33. Johnson, S., Domínguez-García, V., Donetti, L. and Muñoz, M.A., 2014. Trophic

563 coherence determines food-web stability. Proceedings of the National Academy of

$564 \quad$ Sciences $111,17923-17928$.

565 34. Kortsch, S., Primicerio, R., Fossheim, M., Dolgov, A.V. and Aschan, M., 2015. Climate

566 change alters the structure of arctic marine food webs due to poleward shifts of boreal

567 generalists. Proceedings of the Royal Society B 282, 20151546.

568 35. Leventer, A.R. and Dunbar, R.B., 1985. Suspended particulate matter in Antarctic coastal

569 waters. Antarctic Journal of United States of America 20, 100-103.

570 36. Link, J.S., 2002. Does food web theory work for marine ecosystems? Marine Ecology

$571 \quad$ Progress Series 230, 1-9.

572 37. Link, J.S., Stockhausen, W.T. and Methratta, E.T., 2005. Food-web theory in marine

573 ecosystems. In: Belgrano, A., Scharler, U.M., Dunne, J., Ulanowicz, R.E. (Eds.), Aquatic

574 food webs: an ecosystem approach. Oxford University Press, Oxford, pp. 98-114.

575 38. Linton, L.R., Davies, R.W. and Wrona, F.J., 1981. Resource utilization indices: an

576 assessment. The Journal of Animal Ecology 50, 283-292.

577 39. Momo, F., Bogazzi, E. and Duttweiler, F., 1998. Amphipods of Potter Cove: community

578 composition, biology and growth. In: Wiencke, C., Ferreyra, G., Arntz, W., Rinaldi, C.

579 (Eds.), The Potter Cove Coastal Ecosystem, Antarctica. Alfred-Wegener Institut (AWI),

$580 \quad$ Bremerhaven, pp. 144-149.

581 40. Montoya, J.M. and Solé, R.V. 2002. Small world patterns in food webs. Journal of

$582 \quad$ Theoretical Biology 214, 405-412.

583 41. Montoya, J.M. and Solé, R.V., 2003. Topological properties of food webs: from real data 584 to community assembly models. Oikos 102, 614-622. 
585 42. Namba, T., Tanabe, K. and Maeda, N., 2008. Omnivory and stability of food webs.

$586 \quad$ Ecological Complexity 5, 73-85.

587 43. Norkko, A., Thrush, S.F., Cummings, V.J., Gibbs, M.M., Andrew, N.L., Norkko, J. and

588 Schwarz, A.M., 2007. Trophic structure of coastal Antarctic food webs associated with

589 changes in sea ice and food supply. Ecology 88, 2810-2820.

590 44. Opitz, S., 1996. Trophic Interactions in Caribbean Coral Reefs. International Center for

$591 \quad$ Aquatic Resources, Manila, $341 \mathrm{pp}$.

592 45. Pakhomov, E.A. and Perissinotto, R., 1996. Trophodynamics of the hyperiid amphipod

593 Themisto gaudichaudi in the South Georgia region during late austral summer. Marine

594 Ecology Progress Series 134, 91-100.

595 46. Pasotti, F., Manini, E., Giovannelli, D., Wölfl, A.C., Monien, D., Verleyen, E.,

596 Braeckman, U., Abele, D. and Vanreusel, A., 2015a. Antarctic shallow water benthos in

597 an area of recent rapid glacier retreat. Marine Ecology 36, 716-733.

598 47. Pasotti, F., Saravia, L.A., De Troch, M., Tarantelli, M. S., Sahade, R. and Vanreusel, A.,

599 2015b. Benthic Trophic Interactions in an Antarctic Shallow Water Ecosystem Affected

$600 \quad$ by Recent Glacier Retreat. PloS One 10, e0141742.

601 48. Petchey, O.L., Brose, U. and Rall, B.C., 2010. Predicting the effects of temperature on

602 food web connectance. Philosophical Transactions of the Royal Society of London B:

603 Biological Sciences 365, 2081-2091.

604 49. Pimm, S.L., Lawton, J.H. and Cohen, J.E., 1991. Food web patterns and their

605 consequences. Nature 350, 669-674.

606 50. Polis, G.A., 1991. Complex trophic interactions in deserts: an empirical critique of food-

607 web theory. The American Naturalist 138, 123-155. 
608 51. Post, D.M., 2002. The long and short of food-chain length. Trends in Ecology and $609 \quad$ Evolution 17, 269-277.

610 52. Quartino, M.L., Zaixso, H. and Boraso de Zaixso, A.B., 2005. Biological and

611 environmental characterization of marine macroalgal assemblages in Potter Cove, South

612 Shetland Islands, Antarctica. Botanica Marina 48, 187-197.

613 53. Quartino, M.L., Boraso de Zaixso, A.B. and Momo, F.R., 2008. Macroalgal production

614 and the energy cycle of Potter Cove. In: Wiencke, C., Ferreyra, G.A., Abele, D.,

615 Marenssi, S. (Eds.), The Antarctic ecosystem of Potter cove, King-George Island (Isla 25

616 de Mayo). Alfred-Wegener Institut (AWI), Bremerhaven, pp. 68-74.

617 54. Quartino, M.L., Deregibus, D., Campana, G.L., Latorre, G.E.J. and Momo, F.R., 2013.

618 Evidence of macroalgal colonization on newly ice-free areas following glacial retreat in

619 Potter Cove (South Shetland Islands), Antarctica. PLoS One 8, e58223.

620 55. R Core Team, 2016. R: A language and environment for statistical computing. R

621 Foundation for Statistical Computing, Vienna, Austria. ISBN 3-900051-07-0, URL

622 http://www.R-project.org.

623 56. Raffaelli, D., 2000. Trends in research on shallow water food webs. Journal of

$624 \quad$ Experimental Marine Biology and Ecology 250, 223-232.

625 57. Rezende, E.L., Albert, E.M., Fortuna, M.A. and Bascompte, J., 2009. Compartments in a

626 marine food web associated with phylogeny, body mass, and habitat structure. Ecology

$627 \quad$ Letters $12,779-788$.

628 58. Richard, M.G., 1977. The ecology (including physiological aspects) of selected Antarctic

629 marine invertebrates associated with inshore macrophytes. Ph.D. Thesis, Durham

630 University. Durham, USA. 
631 59. Riede, J.O., Rall, B.C., Banasek-Richter, C., Navarrete, S.A., Wieters, E.A., Emmerson,

632 M.C., Jacob, U. and Brose, U., 2010. Scaling of food-web properties with diversity and 633 complexity across ecosystems. Advances In Ecological Research 42, 139-170.

634 60. Roese, M. and Drabble, M., 1998. Wind driven circulation in Potter Cove. In: Wiencke, 635 C., Ferreyra, G., Arntz, W., Rinaldi, C. (Eds.), The Potter Cove Coastal Ecosystem, 636 Antarctica. Alfred-Wegener Institut (AWI), Bremerhaven, pp. 40-46.

637 61. Sahade, R., Lagger, C., Torre, L., Momo, F.R., Monien, P., Schloss, I., Barnes, D.K.A., 638 Servetto, N. Tarantelli, S. Tatián, M., Zamboni, N. and Abele, D., 2015. Climate change 639 and glacier retreat drive shifts in an Antarctic benthic ecosystem. Science Advances 1, $640 \quad \mathrm{e} 1500050$.

641 62. Stouffer, D.B., Camacho, J., Guimera, R., Ng, C.A. and Nunes Amaral, L.A., 2005.

642 Quantitative patterns in the structure of model and empirical food webs. Ecology 86, $643 \quad 1301-1311$.

644 63. Tatián, M., Sahade, R. and Esnal, G.B., 2004. Diet components in the food of Antarctic 645 ascidians living at low levels of primary production. Antarctic Science 16, 123-128. 646 64. Vandermeer, J., 2006. Omnivory and the stability of food webs. Journal of Theoretical $647 \quad$ Biology 238, 497-504.

648 65. Varela, L., 1998. Hydrology of Matías and Potter Creeks. In: Wiencke, C., Ferreyra, G., 649 Arntz, W., Rinaldi, C. (Eds.), The Potter Cove Coastal Ecosystem, Antarctica. Alfred650 Wegener Institut (AWI), Bremerhaven, pp. 33- 39.

651 66. Walther, G.R., 2010. Community and ecosystem responses to recent climate change. 652 Philosophical Transactions of the Royal Society B: Biological Sciences 365, 2019-2024. 
653 67. Watts, D.J. and Strogatz, S.H., 1998. Collective dynamics of 'small-world'networks.

$654 \quad$ Nature 393, 440-442.

655 68. Wiencke, C., Ferreyra, G., Arntz, W. and Rinaldi, C., 1998. The Potter Cove Coastal

656 Ecosystem, Antarctica. Alfred-Wegener Institut (AWI), Bremerhaven, 299 pp.

657 69. Wiencke, C., Ferreyra, G.A., Abele, D. and Marenssi, S., 2008. The Antarctic ecosystem

658 of Potter cove, King-George Island (Isla 25 de Mayo): Synopsis of research performed

659 1999-2006 at the Dallmann Laboratory and Jubany Station. Berichte zur Polar-und

660 Meeresforschung. Alfred-Wegener Institut (AWI), Bremerhaven, 407 pp.

661 70. Williams, R.J. and Martinez, N.D., 2004. Limits to trophic levels and omnivory in

662 complex food webs: theory and data. The American Naturalist 163, 458-468.

663 71. Wirta, H.K., Vesterinen, E.J., Hambäck, P.A., Weingartner, E., Rasmussen, C.,

664 Reneerkens, J., Schmidt, N.M., Gilg, O. and Roslin, T., 2015. Exposing the structure of

665 an Arctic food web. Ecology and Evolution 5, 3842-3856.

666 72. Woodward, G., Benstead, J.P., Beveridge, O.S., Blanchard, J., Brey, T., Brown, L.E.,

667 Cross, W.F., Friberg, N, Ings, T.C., Jacob, U., Jennings, S., Ledger, M.E., Milner, A.M., 668 Montoya, J.M., O’Gorman, E., Olesen, J.M., Petchey, O.L., Pichler, D.E., Reuman, D.C.,

669 Thompson, M.S.A., van Veen, F.J.F. and Yvon-Durocher, G., 2010. Ecological networks

670 in a changing climate. Advances in Ecological Research 42, 71-138.

671 73. Woodward, G., Thompson, R., Townsend, C.R. and Hildrew, A.G., 2005. Pattern and

672 process in food webs: evidence from running waters. In: Belgrano, A., Scharler, U.M.,

673 Dunne, J., Ulanowicz, R.E. (Eds.), Aquatic food webs: an ecosystem approach. Oxford

$674 \quad$ University Press, Oxford, pp. 51-66. 
675 74. Xiao, X., White, E.P., Hooten, M.B. and Durham, S.L., 2011. On the use of

676 log-transformation vs. nonlinear regression for analyzing biological power laws. Ecology

$67792,1887-1894$.

678 75. Yachi, S. and Loreau, M., 1999. Biodiversity and ecosystem productivity in a fluctuating

679 environment: the insurance hypothesis. Proceedings of the National Academy of Sciences

$680 \quad 96,1463-1468$.

681 76. Yodzis, P., 1998. Local trophodynamics and the interaction of marine mammals and

682 fisheries in the Benguela ecosystem. Journal of Animal Ecology 67, 635-658.

683 
bioRxiv preprint doi: https://doi org/10.1101/094557- this version posted October 20,2017 . The copyright holder for this preprint (which was not certified by peer review) is the author/funder, who has granted bioRxiv a license to display the preprint in perpetuity. It is made available under aCC-BY 4.0 International license.

\section{Appendices}

685 Supplementary material Appendix A and B are available at DOI 10.6084/m9.figshare.4498715. 